\title{
Flaxseed oil supplementation alters the expression of inflammatory-related genes in dogs
}

\author{
D. Purushothaman ${ }^{1}$, W.Y. Brown ${ }^{1}$, B.A. Vanselow ${ }^{2}$, K. Quinn ${ }^{2}$ and \\ S.-B. $\mathrm{Wu}^{1}$ \\ ${ }^{1}$ School of Environmental and Rural Science, \\ University of New England, Armidale, NSW, Australia \\ ${ }^{2}$ New South Wales Department of Primary Industries, Beef Industry Centre, \\ University of New England, Armidale, NSW, Australia
}

Corresponding author: S.-B. Wu

E-mail: shubiao.wu@une.edu.au

Genet. Mol. Res. 13 (3): 5322-5332 (2014)

Received May 27, 2013

Accepted September 9, 2013

Published July 24, 2014

DOI http://dx.doi.org/10.4238/2014.July.24.11

\begin{abstract}
Long chain $n-3$ fatty acids are beneficial to mammals because of their anti-inflammatory role. However, whether flaxseed oil, which is rich in short chain $n-3$ fatty acids, has such a role, it has not been extensively examined. This study investigated the supplementation of flaxseed oil on the regulation of genes involved in inflammatory responses such as heat shock proteins (HSP90 and HSP70) and interleukin $(I L 1 \beta)$ in the white blood cells of dogs. Five beagles and 5 greyhounds were supplemented with Melrose ${ }^{\circledR}$ flaxseed oil at the rate of $100 \mathrm{~mL} / \mathrm{kg}$ food for 21 days. The blood was collected at day 0,15 , and 22 following supplementation. The expression of 3 genes was quantified using real-time polymerase chain reaction. Plasma concentrations of fatty acids such as alpha linolenic acid, eicosapentaenoic acid, docosahexaenoic acid, linoleic acid, and arachidonic acid were measured, and their correlations with changes in gene expression were determined. Flaxseed oil supplementation downregulated the
\end{abstract}


expression of $H S P 90$ and $I L 1 \beta$ in greyhounds but showed no significant effect on these genes in beagles. HSP70 remained unchanged in both breeds following the supplementation. Correlations of HSP 90 and $I L 1 \beta$ expression levels with the plasma fatty acid concentrations on day 22 showed a significant negative correlation in greyhounds. Dietary flaxseed oil altered the expression of genes involved in inflammation in white blood cells. Because the expression of the genes may vary in different breeds, it will be useful to consider breed responses to dietary manipulation in canine nutrition management.

Key words: Flaxseed oil; HSP90; IL1 $\beta$; Dog

\section{INTRODUCTION}

Long chain $n$-3 fatty acids (LCn-3FA) are beneficial to mammals because of their antiinflammatory role (Wall et al., 2010). Such role has been demonstrated in the relief of several human inflammatory diseases such as cardiovascular disease (Kris-Etherton et al., 2002; Adkins and Kelley, 2010), rheumatoid arthritis, inflammatory bowel disease, and asthma (Calder, 2006). With recent advances in molecular biological technology and the availability of enormous genetic data in the public database, attention has been diverted to the understanding of the influence of LCn-3FA on the expression of genes involved in immune responses. Using a whole genome transcriptomic analysis, Bouwens et al. (2009) demonstrated a change in gene expression of 1040 genes involved in inflammatory- and atherogenic-related pathways in blood mononuclear cells when human subjects consumed $1.8 \mathrm{~g}$ eicosapentaenoic acid (EPA) and docosahexaenoic acid (DHA) per day for 26 weeks, which further emphasized the potential beneficial effects of LCn-3FA. However, it is reported that fish consumption has been reduced because of the high cost and diminishing global fish stock sources (Brunner et al., 2009) and increasing levels of methyl mercury in fish (Mahaffey, 2004). Hence, there is a need to investigate plant-based sources of $n$-3FA.

Alpha linolenic acid (ALA) is the precursor of LCn-3FA. Present in green leafy vegetables, certain seed oils, beans, and nuts (Sinclair et al., 2002), it is abundant in flaxseed oil, which has an ALA content of 53\% (Barceló-Coblijn and Murphy, 2009). The ability to elongate ALA to LCn-3FA such as EPA and DHA is limited in humans (Burdge and Calder, 2005) and varies between men and women (Burdge, 2004). It has been demonstrated that dietary ALA from flaxseed oil reduces inflammation by decreasing the production of inflammatory cytokines, lipids, and lipoproteins (Zhao et al., 2004, 2007). However, the exact mechanism underlying the role of dietary ALA per se is not clear. To the best of our knowledge, no report has been published on the impact of flaxseed oil on the expression of white blood cell inflammatory genes in animals or humans. It has been reported, however, that $n$-3FA up- or downregulates the expression of genes through their interaction with respective transcription factors in vitro or in the immune system - the lymphocytes (Sampath and Ntambi, 2004). It is not clear yet whether the mechanism involves the direct interaction between $n$-3FA and the transcription factors or an indirect role of $n$-3FA through the metabolic pathways leading to the activation of transcription factors. Pure sodium salts of ALA and ALA from fruit sources have been studied, and the results showed that the ALA exhibits an anti-inflammatory role by 
inhibiting a transcription factor (nuclear factor; NF- $\mathrm{BB}$ ) via the activation of another transcription factor (peroxisome proliferator activated receptor- $\gamma$; PPAR $\gamma$ ) (Zhao et al., 2005; Ren and Chung, 2007). However, the influence of ALA from flaxseed oil on gene expression in the white blood cell has not been investigated.

Beneficial impacts on canine health have been shown in dogs that were supplemented with LCn-3FA such as EPA and DHA (Campbell, 1993; Bauer, 2008; Ramadeen et al., 2010). Canine in vitro studies investigating the influence of $\mathrm{LCn}$-3FA on isolated peripheral blood mononuclear cells showed no influence on cytokine gene expression (Stehle et al., 2010). Previous studies in humans using LCn-3FA from fish sources have demonstrated changes in the gene expression of heat shock proteins (Gorjao et al., 2006) and inflammatory cytokines (Weaver et al., 2009). Additionally, it has been shown that dogs can elongate ALA to EPA, but not to DHA, with the supplementation of dietary flaxseed (Bauer et al., 1998; Dunbar et al., 2010; Purushothaman et al., 2011). However, the impact of short chain $n$-3FA (SCn-3FA) on gene expression has not been investigated in dogs, nor have breed differences been examined.

This study aims to test the hypothesis that ALA-rich flaxseed oil will alter the expression of genes involved in inflammation, in a similar manner as fish oil in dogs, and to see if breed differences exist. This study will answer 3 questions. First, do the expression levels of inflammatory genes in white blood cells change as a result of flaxseed oil supplementation? Second, do two different breeds respond differently to the same supplementation regime? Third, do the changes observed in gene expression correlate with changes in plasma fatty acid composition?

\section{MATERIAL AND METHODS}

\section{Animals and diet}

We used 5 beagles and 5 greyhounds, all females, aged between 2 and 9 years and weighing an average of $12.4 \pm 1.2$ and $25.6 \pm 2.0 \mathrm{~kg}$, respectively, at the start of the study. These dogs were housed at the University of New England (UNE) dog research facilities at Armidale, NSW, Australia. Only dogs that were healthy upon veterinary inspection on the day of arrival were selected for the study.

All dogs were fed a nutritionally complete and balanced commercial dog food (substantiated by the Association of American Feed Control Officials feeding protocol) for 4 months, with ad libitum access to water. Diets were then supplemented with Melrose ${ }^{\circledR}$ flaxseed oil containing $57 \%$ ALA and $17 \%$ linoleic acid (LA) at the rate of $100 \mathrm{~mL} / \mathrm{kg}$ food, which equated to $2.4 \pm 0.2 \mathrm{~mL} / \mathrm{kg}$ body weight (30 mL/beagle and $60 \mathrm{~mL} /$ greyhound) for 3 weeks. Diets were offered once daily ( $300 \mathrm{~g}$ for beagles and $600 \mathrm{~g}$ for greyhounds), and there were no refusals during the 3 -week supplementation period. The detailed composition of the basal and supplementation diets has been described previously (Purushothaman et al., 2011).

The care and use of all the animals in this study followed the guidelines set by the UNE Animal Ethics Committee (Authority No. AEC09/072), in accordance with section 25 of the Animal Research Act (1985).

\section{White blood cell harvest and RNA extraction}

Whole blood samples from beagles $(20 \mathrm{~mL})$ and greyhounds $(50 \mathrm{~mL})$ were collected 
from the jugular vein at fasting state on day 0 (pre-supplementation), 15, and 22, and they were immediately transferred into ethylenediaminetetraacetic acid (EDTA)-coated vials. White blood cells (WBCs) were extracted using a modified protocol of ammonium chloride lysis of erythrocytes (Muirhead et al., 1986). One part whole blood was mixed with 5 parts $1 \mathrm{X}$ ammonium chloride erythrocyte lysing reagent $\left(0.1 \mathrm{mM}\right.$ EDTA, $150 \mathrm{mM} \mathrm{NH}_{4} \mathrm{Cl}$, and 10 $\mathrm{mM} \mathrm{NaHCO}$ ) and incubated on ice for 45 min until complete lysis of erythrocytes occurred. The WBC pellet was obtained after centrifugation at $2000 \mathrm{~g}$ for $5 \mathrm{~min}$ at $4^{\circ} \mathrm{C}$. This procedure was repeated twice to remove erythrocyte remnants found in the WBC pellet. Total RNA of the WBC pellet was extracted using Trizol reagent (Life Technologies, Mulgrave,VIC, Australia) and further purified with RNeasy Mini Kit (Qiagen, Clifton Hill, VIC, Australia) following manufacturers' instructions. The RNA yield was quantified using NANODROP Spectrophotometer (NanoDrop Technologies, Wilmington, DE, USA), and the integrity of RNA was assessed on 1.2\% agarose gels stained with 1:50 concentration Gelstar nucleic acid stain (Cambrex, Rockland, ME, USA).

\section{Reverse transcription and real-time polymerase chain reaction (PCR) analysis}

cDNA was synthesized by a 2-step process using the cDNA Synthesis Kit (Bioline, Sydney, NSW, Australia) following the manufacturer protocol. A negative control was performed by negating the reverse transcriptase. Quantitative real time PCR was performed using a Rotor-Gene 6000 real-time PCR Thermocycler (Corbett Research, Mortlake, NSW, Australia) in a $10-\mu \mathrm{L}$ reaction mixture that contained $1 \mathrm{X}$ PCR buffer (Bioline), $1.5 \mathrm{mM} \mathrm{MgCl}, 0.2$ $\mathrm{mM}$ dNTP, $0.5 \mu \mathrm{M}$ forward primer, $0.5 \mu \mathrm{M}$ reverse primer, $0.5 \mathrm{U}$ Biotaq DNA polymerase (Bioline), $1.5 \mu \mathrm{M}$ Syto9 green fluorescent nucleic acid stain (Invitrogen, Sydney, NSW, Australia), and $25 \mathrm{ng}$ cDNA. The primers were manually designed using the Primer 3 and Net Primer programs following the principle for the primer design that was used in the quantitative PCR assay (Table 1). B2M was chosen as the housekeeping gene after the initial test and validation together with other housekeeping gene candidates HPRT1, RPS7, and RLP8. The real-time PCR conditions were achieved with the following steps: the mixture was preheated to $50^{\circ} \mathrm{C}$ for $2 \mathrm{~min}$, and then it was denatured at $95^{\circ} \mathrm{C}$ for 10 min followed by 40 cycles of denaturation for $15 \mathrm{~s}$, annealing at $60^{\circ} \mathrm{C}$ for $30 \mathrm{~s}$, and extension at $72^{\circ} \mathrm{C}$ for $60 \mathrm{~s}$. A final extension step was performed at $72^{\circ} \mathrm{C}$ for $2 \mathrm{~min}$. The fluorescence signals were collected at the end of each annealing step during the PCR cycles. The melting curve analysis was performed to assess the specificity of the PCR amplification and primer quality, and it was achieved by increasing the temperature of the reaction following PCR cycles from $50^{\circ}$ to $99^{\circ} \mathrm{C}$, with an increment rate of $1^{\circ} \mathrm{C}$ every $5 \mathrm{~s}$. The sizes of the PCR products were determined on $1.2 \%$ agarose gel and stained with a 1:50 concentration Gelstar nucleic acid stain (Cambrex) to confirm the specificity of the amplification.

Table 1. Sequences of the primers for $B 2 M, H S P 90, H S P 70$, and $I L 1 \beta$.
\begin{tabular}{lllrc}
\hline Gene & Forward primer & Reverse primer & Amplicon $(\mathrm{bp})$ & $\mathrm{Ta}\left({ }^{\circ} \mathrm{C}\right)$ \\
\hline$B 2 M$ & TAAGTGGGACCGAGACAACTGA & AGTGACACAGTGCCCAATGTAGA & 181 & 60.0 \\
$H S P 90$ & GCAGAGAGAGGAAGAAGCTATTCA & CCTCATTCCAGCAAGAGCAT & 245 & 60.0 \\
$H S P 70$ & GGGGAGGACTTCGACAACAG & AAGTCGATGCCCTCGAACAG & 191 & 60.0 \\
$I L 1 \beta$ & ACAAACAAGTGGTGTTCACATG & TGGGCTTCCATCCTTCATC & 126 & 60.0 \\
\hline
\end{tabular}


To quantify the relative gene expression level, a comparative cycle threshold $(\mathrm{Ct})$ method was used (Schmittgen and Livak, 2008). cDNA samples were amplified in duplicates for target genes and the $B 2 M$ housekeeping gene. The fluorescence $\mathrm{Ct}$ values were automatically detected using the quantitation analysis module of the Rotor-Gene 6000 series software (Corbett Research, Sydney, NSW, Australia). $\Delta \mathrm{Ct}$ values were then calculated by the difference in $\mathrm{Ct}$ values of the candidate gene and the housekeeping genes. These values were then used for statistical analysis. Additionally, for quality control, a standard dilution curve was constructed using the quantitation analysis program of the Rotor-Gene 6000 series software (Corbett Research) to assess the amplification efficiency of the PCR.

\section{Plasma fatty acid analysis}

Plasma was extracted from sub-samples of whole blood (above) by centrifugation at $1900 \mathrm{~g}$ for $15 \mathrm{~min}$ at $4^{\circ} \mathrm{C}$. The fatty acid composition was analyzed using an acetyl chloride methylation procedure (Munro and Garg, 2013). Fatty acid methyl esters such as ALA, EPA, DHA, LA, and arachidonic acid (AA) were measured by gas chromatography (Hewlett Packard 6890, Hewlett Packard, Palo Alto, CA, USA) and identified by comparing peak retention times with the retention times of synthetic standards of known fatty acid composition $(\mathrm{Nu}$ Check Prep, Elysian, MN, USA). Each fatty acid concentration is expressed as a percentage of the total fatty acid content.

\section{Statistical methods}

Windows MINITAB Version 14 (Minitab Limited, Coventry, WMD, UK) was used for statistical analysis. For all of the analyses, a $\mathrm{P}$ value $<0.05$ was considered to be statistically significant. Breed differences in gene expression with respect to day of supplementation were determined using a general linear model (GLM), with breed and day as main effects and with age and body weight as random factors. Within a particular breed, one-way analysis of variance (ANOVA) was used to analyze the effect of flaxseed oil supplementation on gene expression. For each plasma fatty acid constituent, within a particular breed, one-way ANOVA was used to analyze the change in concentration with the day of supplementation. The correlation between plasma fatty acid concentrations and the levels of gene expression was examined using the Pearson correlation coefficient.

\section{RESULTS AND DISCUSSION}

\section{Different gene expression between two breeds}

Because the age and body weight did not contribute to the expression of all 3 genes as random factors, the GLM model without random factors was used to evaluate the effect of breed, day, and breed $\mathrm{x}$ day interaction. The level of gene expression (HSP90 and IL1 $\beta$ ) was significantly different between the 2 breeds (Table 2). Beagles had higher expression of these 2 genes than greyhounds. However, days of treatment did not show a significant effect on the expression of both genes. No significant interaction was observed between breed and day. 
Table 2. Differential expression of the HSP90, HSP70 and $I L 1 \beta$ genes $(\triangle \mathrm{Ct})$ in the greyhounds and beagles.

\begin{tabular}{lccc}
\hline Treatment & $H S P 90$ & $H S P 70$ & $I L 1 \beta$ \\
\hline Main effect & & & \\
Breed & & & \\
$\quad$ Greyhound & 5.91 & 12.22 & 11.26 \\
Beagle & 4.92 & 13.26 & 10.05 \\
Day & & 12.86 & 10.06 \\
0 & 5.01 & 12.04 & 10.51 \\
15 & 5.45 & 13.31 & 11.39 \\
22 & 5.79 & & 0.035 \\
GLM (P) & & NS & NS \\
Breed & 0.045 & NS & NS \\
Day & NS & NS & \\
Breed x day & NS & & \\
\hline
\end{tabular}

It has been previously reported that $\mathrm{LC} n$-3FA metabolism is genetically regulated, as demonstrated in different transgenic strains of mice (Ko et al., 2003). This is consistent with the findings of our previous study, wherein breed differences in dogs were demonstrated for LCn-3FA metabolism when plasma $n$-3FA was analyzed (Purushothaman et al., 2011). However, in this study, the expression levels of the 3 genes were different in both breeds even prior to supplementation. Greyhounds showed differential expression of the HSP90 and ILI $\beta$ genes following the supplementation of flaxseed oil. However, such changes were not observed in beagles. The differential gene expression observed only in greyhounds could be because of their higher plasma concentrations of ALA and EPA compared to the beagles on day 22 postsupplementation of flaxseed oil. Prior to supplementation, the plasma concentrations of ALA were lower in greyhounds than in beagles. As the supplemented diet had 52 times more ALA than the basal diet had (Purushothaman et al., 2011), it is likely that the greater change of ALA in the body caused the greyhounds to respond by downregulating the $H S P 90$ and $I L 1 \beta$ genes.

\section{Flaxseed supplementation downregulated the expression of $H S P 90$ and $I L 1 \beta$ in greyhounds, which correlated with the plasma fatty acid concentrations}

The gene expression levels were investigated independently in each breed. The values used for analysis were $\Delta \mathrm{Ct}$ so that an increase in $\triangle \mathrm{Ct}$ indicates a decrease in gene expression. In the WBCs of the greyhound, the expression of both genes (HSP90 and IL1 $\beta$ ) significantly decreased on day 22 of the flaxseed oil supplementation in comparison with those on day 0 , i.e., before the supplementation took place (Figure 1). The average $\triangle \mathrm{Ct}$ value of $H S P 90$ increased from 4.8 to 6.5 , and that of $I L 1 \beta$ increased from 10.9 to 12.2 . On day 15 , the flaxseed oil downregulated $H S P 90$ gene expression and the $\triangle \mathrm{Ct}$ values changed from 4.8 to 6.4 , whereas the expression level of $I L 1 \beta$ did not change. In contrast, the expression levels of the HSP70 gene did not show significant alterations on either day 15 or 22 of flaxseed supplementation in the greyhounds. The expression levels of these 3 genes were not significantly affected by the supplementation of flaxseed oil in the beagle.

Of the 5 fatty acids that were studied, plasma ALA and EPA significantly increased from day 0 to day 22 in both breeds (Figure 2). Plasma DHA and AA did not significantly change in either breed, while plasma LA significantly increased in only greyhounds and not in beagles. Regression analysis of the expression levels of the $H S P 90$ and $I L 1 \beta$ genes in greyhounds against the concentrations of the plasma fatty acids was performed to investigate 
whether the expression alterations were associated with the levels of plasma fatty acids. Plasma levels of ALA and EPA showed significant positive correlations with the $\triangle \mathrm{Ct}$, and negative correlations with the expression of $H S P 90(\mathrm{r}=0.654$ and 0.527 , respectively) and $I L 1 \beta(\mathrm{r}=$ 0.375 and 0.372 , respectively) (Table 3$)$. A trend $(\mathrm{P}<0.10)$ was detected between $I L 1 \beta$ gene expression and the plasma fatty acid concentrations of ALA and EPA. No significant correlation was observed between the other fatty acids (DHA, LA, and AA) and gene expression data. The plasma fatty acid concentration in the beagles showed no significant correlation with any of the 3 genes that were investigated.

A

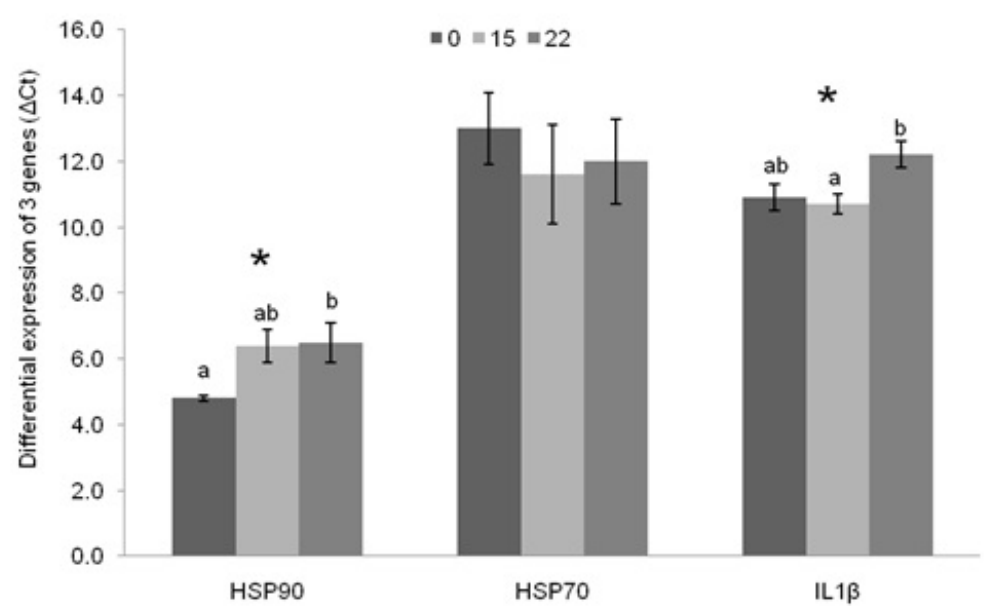

B

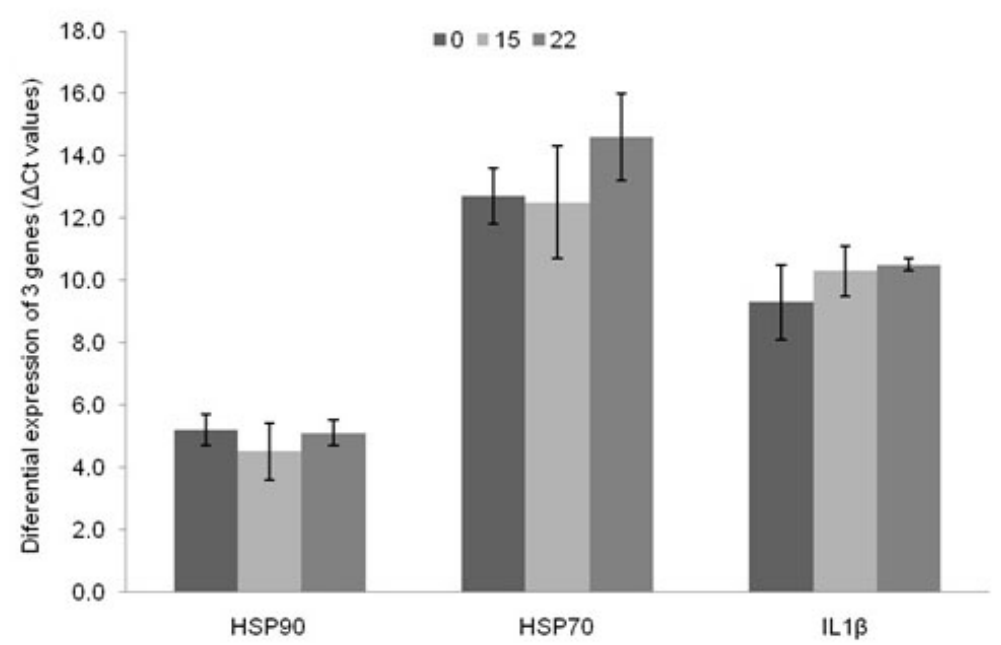

Figure 1. Differential expressions of the HSP90, HSP70 and $I L 1 \beta$ genes following flaxseed oil supplementation in the two breeds. A. In greyhounds. B. In beagles. Error bars represent the standard error of the mean. ${ }^{\mathrm{a}, \mathrm{b}}$ Means between columns without a common superscript differ significantly. ${ }^{*} \mathrm{P}<0.05$. 
A

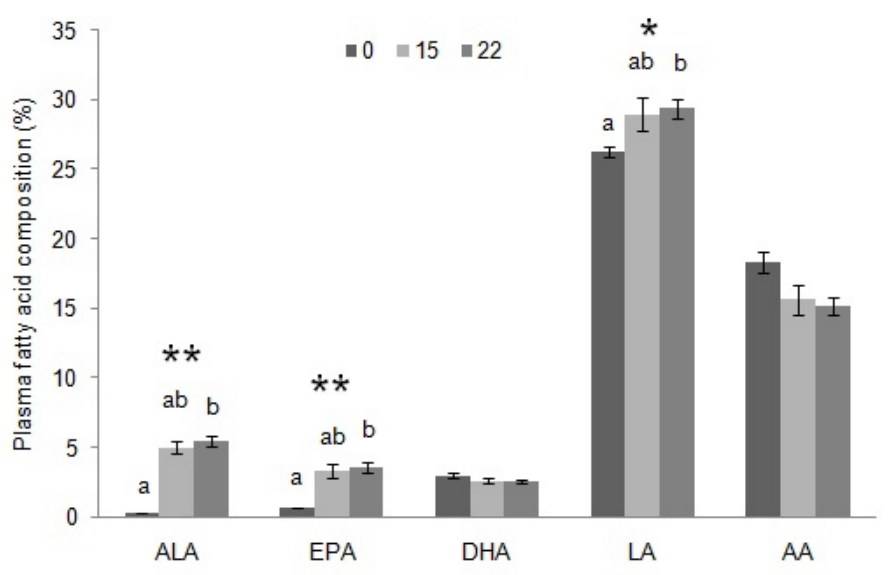

B

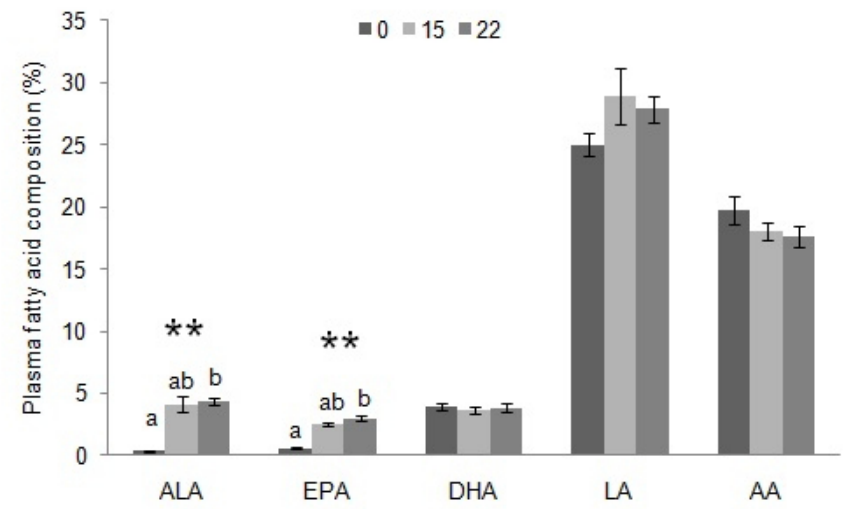

Figure 2. Plasma fatty acid compositions of alpha linoleic acid (ALA), eicosapentaenoic acid (EPA), docosahexaenoic acid (DHA), linoleic acid (LA), and arachidonic acid (AA) in percentages following flaxseed oil supplementation in the two breeds. A. In greyhounds. B. In beagles. Error bars represent the standard error of the mean. ${ }^{\mathrm{a}, \mathrm{b}}$ Means between columns without a common superscript differ significantly. ${ }^{*} \mathrm{P}<0.05,{ }^{*} \mathrm{P}<0.01$.

Table 3. Pearson's correlation coefficients between plasma concentrations of alpha linoleic acid (ALA), eicosapentaenoic acid (EPA), docosahexaenoic acid (DHA), linoleic acid (LA), and arachidonic acid (AA) fatty acids and the expression of $H S P 90, H S P 70$ and $I L 1 \beta$ in greyhounds and beagles.

\begin{tabular}{|c|c|c|c|c|c|c|}
\hline & \multicolumn{3}{|c|}{ Greyhounds $(\mathrm{N}=5)$} & \multicolumn{3}{|c|}{ Beagles $(\mathrm{N}=5)$} \\
\hline & HSP 90 & HSP70 & $I L I B$ & HSP90 & HSP70 & $I L 1 B$ \\
\hline ALA & $0.654^{*}$ & -0.260 & $0.375^{* *}$ & -0.183 & -0.032 & 0.360 \\
\hline EPA & $0.527 *$ & -0.272 & $0.372 * *$ & -0.190 & 0.299 & 0.296 \\
\hline DHA & -0.294 & -0.161 & -0.142 & -0.110 & 0.138 & 0.038 \\
\hline LA & 0.408 & -0.347 & 0.367 & -0.201 & -0.137 & 0.126 \\
\hline AA & -0.409 & -0.138 & -0.181 & -0.026 & -0.052 & 0.157 \\
\hline
\end{tabular}

*Values denote significant $\mathrm{P}$ values $(\mathrm{P}<0.05)$. **Values denote trends $(\mathrm{P}<0.10)$.

It has been reported that supplementation with LCn-3FA often leads to the differential expression of genes involved in inflammatory-related metabolic pathways (Simopoulos, 2002; Calder, 2006; Deckelbaum et al., 2006). Fish oil addition in diets for humans and 
animals has been studied extensively to assess the role of $n-3 \mathrm{FA}$ in regulating the immune system, which directly responds to inflammation-related disorders (Fisher et al., 1986; Yoshino and Ellis, 1987; LeBlanc et al., 2008). However, flaxseed oil supplementation in animal diets as a fish oil replacement has only been reported in a limited number of studies (Caughey et al., 1996; Mueller et al., 2005; Park et al., 2011). Further, to the best of our knowledge, no gene expression studies have been reported to investigate the response of genes to flaxseed oil supplementation. The major component of fatty acids in flaxseed oil is ALA (Cunnane et al., 1993), which has been reported to exhibit an anti-inflammatory role in vitro through $\mathrm{NF}-\kappa \mathrm{B}$ and mitogen-activated protein kinase pathways (Ren and Chung, 2007). In our previous study, supplementation of flaxseed oil in the diets of dogs resulted in increased concentrations of plasma EPA, suggesting that the ALA was elongated to EPA (Purushothaman et al., 2011). In this study, the addition of flaxseed oil in the diets downregulated the $H S P 90$ and $I L 1 \beta$ genes, suggesting that ALA and/or EPA modulated the activities of the genes that are possibly relevant to the inflammatory responses. Moreover, the downregulation of the genes was negatively correlated with the plasma concentrations of ALA and EPA following the 22 days of supplementation. Because ALA performs an anti-inflammatory role in vitro through $\mathrm{NF}-\mathrm{\kappa B}$ and mitogen-activated protein kinase pathways and may activate PPAR $\beta / \delta$ (Zhao et al., 2005; Ren and Chung, 2007), its negative correlations with the $H S P 90$ and $I L 1 \beta$ inflammatory genes may imply an immunosuppressive role in greyhound dogs. On the other hand, the higher concentrations of EPA from ALA elongation may have affected the downregulation of $H S P 90$ and $I L 1 \beta$. EPA has been found to downregulate $I L 1 \beta$ in healthy humans (Weaver et al., 2009). This is consistent with our findings in this study. Therefore, we can speculate that EPA at least has an additive role in the downregulation of $I L 1 \beta$. DHA has been found to upregulate the HSP90 gene in neutrophils and monocytes of healthy humans (Gorjao et al., 2006). In contrast, in our study, the flaxseed oil supplementation downregulated HSP90 in the WBCs of greyhound dogs. It has been shown that different $n$-3FA can have different effects on gene expression and on functions of neutrophils, monocytes, and lymphocytes (Verlengia et al., 2004; Gorjao et al., $2006,2009)$. The roles of ALA or EPA in the regulation of the inflammatory-related genes may be different from that of DHA. Apparently, the regulation of the genes upon the $n$-3FA supplementation was found in different species or different types of cells (Verlengia et al., 2004; Gorjao et al., 2006, 2009). The effect of species differences cannot be completely ruled out. Therefore, further investigations into the regulation of the genes involved in the inflammatory metabolic pathways are warranted.

\section{CONCLUSION}

In conclusion, the findings in this study suggest that dietary ALA supplemented from flaxseed oil altered the expression of genes involved in inflammation in WBCs. Although flaxseed oil supplementation produced similar responses of the genes involved in inflammatory metabolic pathways as fish oil, different $n$-3FA may not always have the same effect on the metabolic responses and gene expression. Furthermore, as the expression of the genes varies in different breeds, which reflects relatively different metabolic activities in the animals, it is important to take breed difference into account in canine nutrition management. 


\section{ACKNOWLEDGMENTS}

Research supported by the University of New England Postgraduate Research Fund. We thank the dog owners Shirley Fraser for providing the beagles and Greg Nordstrom for the greyhounds. We acknowledge Professor Manohar Garg, Director, Nutraceuticals Research Group, University of Newcastle, NSW, Australia, for conducting the fatty acid analysis. We also thank Dr Gilbert Jeyaruban, Animal Genetics Breeding Unit, Armidale, NSW, Australia, for the statistical support.

\section{REFERENCES}

Adkins Y and Kelley DS (2010). Mechanisms underlying the cardioprotective effects of omega-3 polyunsaturated fatty acids. J. Nutr. Biochem. 21: 781-792.

Barceló-Coblijn G and Murphy EJ (2009). Alpha-linolenic acid and its conversion to longer chain $n$-3 fatty acids: benefits for human health and a role in maintaining tissue $n$-3 fatty acid levels. Prog. Lipid Res. 48: 355-374.

Bauer JJE (2008). Essential fatty acid metabolism in dogs and cats. Rev. Bras. Zootecn. 37: 20-27.

Bauer JE, Dunbar BL and Bigley KE (1998). Dietary flaxseed in dogs results in differential transport and metabolism of (n-3) polyunsaturated fatty acids. J. Nutr. 128: 2641S-2644S.

Bouwens M, van de Rest O, Dellschaft N, Bromhaar MG, et al. (2009). Fish-oil supplementation induces antiinflammatory gene expression profiles in human blood mononuclear cells. Am. J. Clin. Nutr. 90: 415-424.

Brunner EJ, Jones PJ, Friel S and Bartley M (2009). Fish, human health and marine ecosystem health: policies in collision. Int. J. Epidemiol. 38: 93-100.

Burdge G (2004). Alpha-linolenic acid metabolism in men and women: nutritional and biological implications. Curr. Opin. Clin. Nutr. Metab. Care 7: 137-144.

Burdge GC and Calder PC (2005). Conversion of alpha-linolenic acid to longer-chain polyunsaturated fatty acids in human adults. Reprod. Nutr. Dev. 45: 581-597.

Calder PC (2006). n-3 polyunsaturated fatty acids, inflammation, and inflammatory diseases. Am. J. Clin. Nutr. 83: 1505S-1519S.

Campbell KL (1993). Clinical use of fatty acid supplements in dogs. Vet. Dermatol. 4: 167-173.

Caughey GE, Mantzioris E, Gibson RA, Cleland LG, et al. (1996). The effect on human tumor necrosis factor alpha and interleukin 1 beta production of diets enriched in $n-3$ fatty acids from vegetable oil or fish oil. Am. J. Clin. Nutr. 63: 116-122.

Cunnane SC, Ganguli S, Menard C, Liede AC, et al. (1993). High alpha-linolenic acid flaxseed (Linum usitatissimum): some nutritional properties in humans. Br. J. Nutr. 69: 443-453.

Deckelbaum RJ, Worgall TS and Seo T (2006). $n$-3 fatty acids and gene expression. Am. J. Clin. Nutr. 83: 1520S-1525S.

Dunbar BL, Bigley KE and Bauer JE (2010). Early and sustained enrichment of serum $n$ - 3 long chain polyunsaturated fatty acids in dogs fed a flaxseed supplemented diet. Lipids 45: 1-10.

Fisher M, Upchurch KS, Levine PH, Johnson MH, et al. (1986). Effects of dietary fish oil supplementation on polymorphonuclear leukocyte inflammatory potential. Inflammation 10: 387-392.

Gorjao R, Verlengia R, Lima TM, Soriano FG, et al. (2006). Effect of docosahexaenoic acid-rich fish oil supplementation on human leukocyte function. Clin. Nutr. 25: 923-938.

Gorjao R, Azevedo-Martins AK, Rodrigues HG, Abdulkader F, et al. (2009). Comparative effects of DHA and EPA on cell function. Pharmacol. Ther. 122: 56-64.

Ko C, O'Rourke SM and Huang LS (2003). A fish oil diet produces different degrees of suppression of apoB and triglyceride secretion in human apoB transgenic mouse strains. J. Lipid Res. 44: 1946-1955.

Kris-Etherton PM, Harris WS and Appel LJ (2002). Fish consumption, fish oil, omega-3 fatty acids, and cardiovascular disease. Circulation 106: 2747-2757.

LeBlanc CJ, Horohov DW, Bauer JE, Hosgood G, et al. (2008). Effects of dietary supplementation with fish oil on in vivo production of inflammatory mediators in clinically normal dogs. Am. J. Vet. Res. 69: 486-493.

Mahaffey KR (2004). Fish and shellfish as dietary sources of methylmercury and the omega-3 fatty acids, eicosahexaenoic acid and docosahexaenoic acid: risks and benefits. Environ. Res. 95: 414-428.

Mueller RS, Fettman MJ, Richardson K, Hansen RA, et al. (2005). Plasma and skin concentrations of polyunsaturated fatty acids before and after supplementation with $n-3$ fatty acids in dogs with atopic dermatitis. Am. J. Vet. Res. 66: 868-873.

Genetics and Molecular Research 13 (3): 5322-5332 (2014) 
Muirhead KA, Wallace PK, Schmitt TC, Frescatore RL, et al. (1986). Methodological considerations for implementation of lymphocyte subset analysis in a clinical reference laboratory. Ann. N. Y. Acad. Sci. 468: 113-127.

Munro IA and Garg ML (2013). Dietary supplementation with long chain omega-3 polyunsaturated fatty acids and weight loss in obese adults. Obes. Res. Clin. Pract. 7: e173-e181.

Park HJ, Park JS, Hayek MG, Reinhart GA, et al. (2011). Dietary fish oil and flaxseed oil suppress inflammation and immunity in cats. Vet. Immunol. Immunopathol. 141: 301-306.

Purushothaman D, Brown WY, Wu SB and Vanselow B (2011). Evaluation of breed effects on $n-3$ PUFA metabolism with dietary flaxseed oil supplementation in dogs. Br. J. Nutr. 106 (Suppl 1): S139-S141.

Ramadeen A, Laurent G, dos Santos CC, Hu X, et al. (2010). n-3 polyunsaturated fatty acids alter expression of fibrotic and hypertrophic genes in a dog model of atrial cardiomyopathy. Heart Rhythm. 7: 520-528.

Ren J and Chung SH (2007). Anti-inflammatory effect of alpha-linolenic acid and its mode of action through the inhibition of nitric oxide production and inducible nitric oxide synthase gene expression via NF-kappaB and mitogen-activated protein kinase pathways. J. Agric. Food Chem. 55: 5073-5080.

Sampath H and Ntambi JM (2004). Polyunsaturated fatty acid regulation of gene expression. Nutr. Rev. 62: 333-339.

Schmittgen TD and Livak KJ (2008). Analyzing real-time PCR data by the comparative $C_{\mathrm{T}}$ method. Nat. Protoc. 3: 1101-1108. Simopoulos AP (2002). Omega-3 fatty acids in inflammation and autoimmune diseases. J. Am Coll. Nutr. 21: 495-505.

Sinclair AJ, Attar-Bashi NM and Li D (2002). What is the role of alpha-linolenic acid for mammals? Lipids 37: 1113-1123.

Stehle ME, Hanczaruk M, Schwarz SC, Gobel TW, et al. (2010). Effects of polyunsaturated fatty acids on isolated canine peripheral blood mononuclear cells and cytokine expression (IL-4, IFN-gamma, TGF-beta) in healthy and atopic dogs. Vet. Dermatol. 21: 112-117.

Verlengia R, Gorjao R, Kanunfre CC, Bordin S, et al. (2004). Comparative effects of eicosapentaenoic acid and docosahexaenoic acid on proliferation, cytokine production, and pleiotropic gene expression in Jurkat cells. J. Nutr. Biochem. 15: 657-665.

Wall R, Ross RP, Fitzgerald GF and Stanton C (2010). Fatty acids from fish: the anti-inflammatory potential of long-chain omega-3 fatty acids. Nutr. Rev. 68: 280-289.

Weaver KL, Ivester P, Seeds M, Case LD, et al. (2009). Effect of dietary fatty acids on inflammatory gene expression in healthy humans. J. Biol. Chem. 284: 15400-15407.

Yoshino S and Ellis EF (1987). Effect of a fish-oil-supplemented diet on inflammation and immunological processes in rats. Int. Arch. Allergy Appl. Immunol. 84: 233-240.

Zhao G, Etherton TD, Martin KR, West SG, et al. (2004). Dietary alpha-linolenic acid reduces inflammatory and lipid cardiovascular risk factors in hypercholesterolemic men and women. J. Nutr. 134: 2991-2997.

Zhao G, Etherton TD, Martin KR, Vanden Heuvel JP, et al. (2005). Anti-inflammatory effects of polyunsaturated fatty acids in THP-1 cells. Biochem. Biophys. Res. Commun. 336: 909-917.

Zhao G, Etherton TD, Martin KR, Gillies PJ, et al. (2007). Dietary alpha-linolenic acid inhibits proinflammatory cytokine production by peripheral blood mononuclear cells in hypercholesterolemic subjects. Am. J. Clin. Nutr. 85: 385-391. 